\title{
Development of Energy Storage: Cost models
}

IES Simulation Ecosystem Control System Development

Nuclear Science and Engineering Division 


\section{About Argonne National Laboratory}

Argonne is a U.S. Department of Energy laboratory managed by UChicago Argonne, LLC under contract DE-AC0206CH11357. The Laboratory's main facility is outside Chicago, at 9700 South Cass Avenue, Argonne, Illinois 60439. For information about Argonne

and its pioneering science and technology programs, see www.anl.gov.

\section{DOCUMENT AVAILABILITY}

Online Access: U.S. Department of Energy (DOE) reports produced after 1991 and a growing number of pre-1991 documents are available free at OSTI.GOV (http://www.osti.gov/), a service of the US Dept. of Energy's Office of Scientific and Technical Information.

Reports not in digital format may be purchased by the public from the

National Technical Information Service (NTIS):

U.S. Department of Commerce

National Technical Information Service

5301 Shawnee Rd

Alexandria, VA 22312

www.ntis.gov

Phone: (800) 553-NTIS (6847) or (703) 605-6000

Fax: (703) 605-6900

Email: orders@ntis.gov

Reports not in digital format are available to DOE and DOE contractors from the Office of Scientific and Technical Information (OSTI):

U.S. Department of Energy

Office of Scientific and Technical Information

P.O. Box 62

Oak Ridge, TN 37831-0062

www.osti.gov

Phone: (865) 576-8401

Fax: (865) 576-5728

Email: reports@osti.gov

\section{Disclaimer}

This report was prepared as an account of work sponsored by an agency of the United States Government. Neither the United States Government nor any agency thereof, nor UChicago Argonne, LLC, nor any of their employees or officers, makes any warranty, express or implied, or assumes any legal liability or responsibility for the accuracy, completeness, or usefulness of any information, apparatus, product, or process disclosed, or represents that its use would not infringe privately owned rights. Reference herein to any specific commercial product, process, or service by trade name, trademark, manufacturer, or otherwise, does not necessarily constitute or imply its endorsement, recommendation, or favoring by the United States Government or any agency thereof. The views and opinions of document authors expressed herein do not necessarily state or reflect those of the United States Government or any agency thereof, Argonne National Laboratory, or UChicago Argonne, LLC. 
ANL/NSE-21/13

\section{Development of Energy Storage: Cost models}

IES Simulation Ecosystem Control System Development

prepared by

Roberto Ponciroli, Haoyu Wang, Richard B. Vilim

Nuclear Science and Engineering Division, Argonne National Laboratory

and

Konor Frick, Cristian Rabiti

Reactor Systems Design \& Analysis Division, Idaho National Laboratory

March 31, 2021 
Development of Energy Storage: Cost models

March 31, 2021 


\section{Table of Contents}

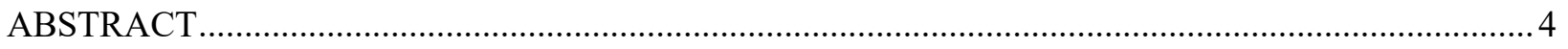

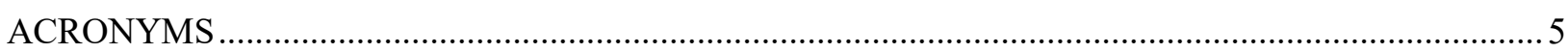

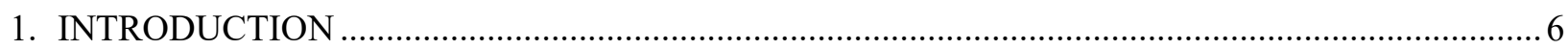

1.1. Short-duration vs Long-duration energy storage technologies ................................................... 6

1.2. Overview of Thermal Energy Storage technologies ................................................................. 6

2. CHARACTERIZATION OF THE ECONOMICS OF TES TECHNOLOGIES ................................. 10

3. ECONOMIC MODEL IMPLEMENTED IN TEAL ….................................................................... 12

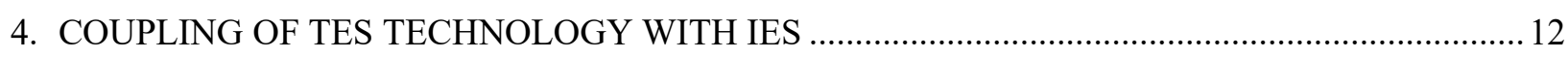

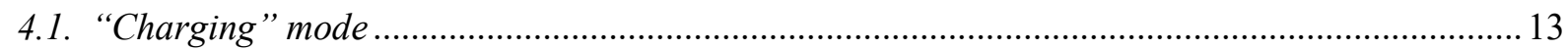

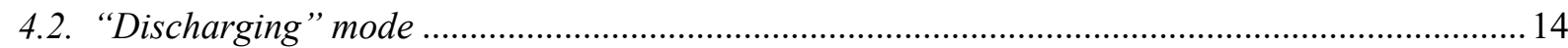

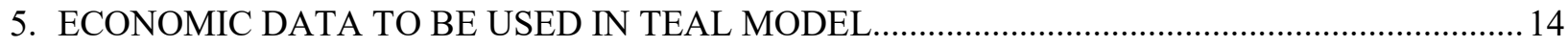

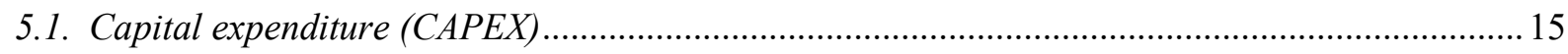

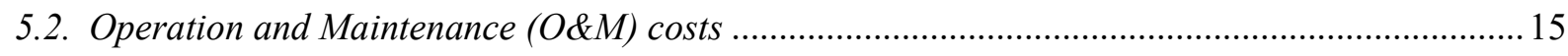

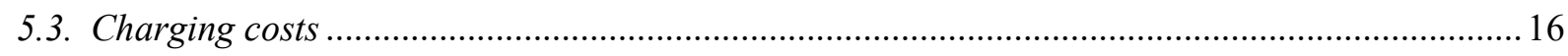

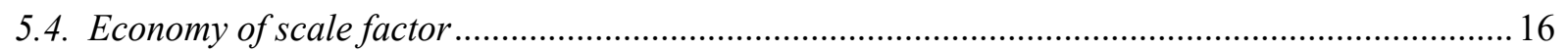

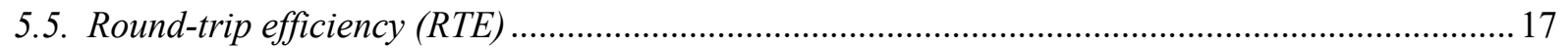

5.6. Installed capacity degradation ............................................................................................. 18

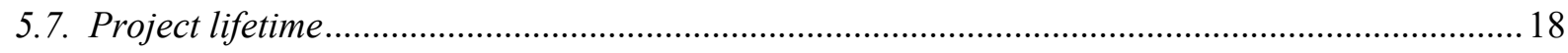

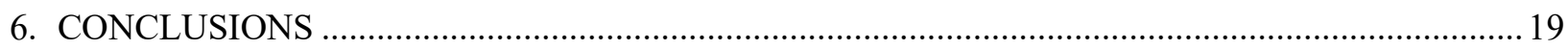

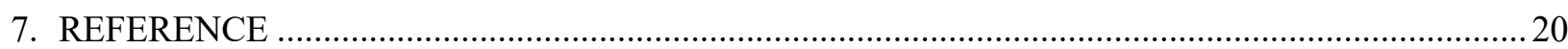




\section{List of Figures}

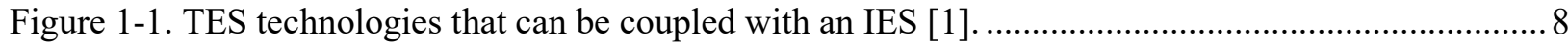

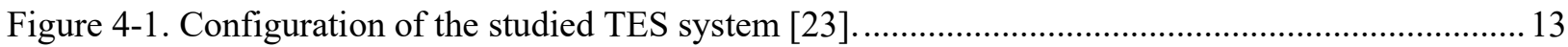

Figure 4-2. TES configuration in (a) "charging mode" and in (b) "discharging mode" [23] ................... 14

Figure 5-1. Schematic of a molten salt power tower showing major subsystems (please refer to [25])..... 15

Figure 5-2. Configuration of the studied TES system. The thermodynamic conditions of the steam

diverted to the TES and the conditions of the steam produced by the IHX are outlined........................... 18 


\section{List of Tables}

Table 1-1. Advantages and disadvantages of TES technologies.......................................................... 7

Table 2-1. Operational and economic parameters characterizing an energy storing technology............... 11

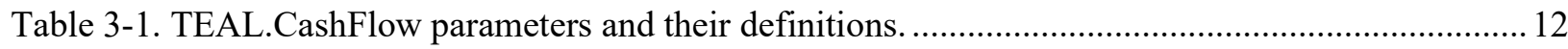

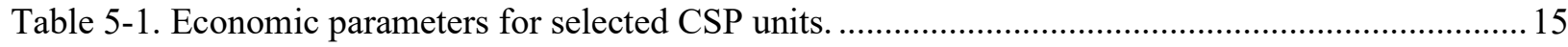

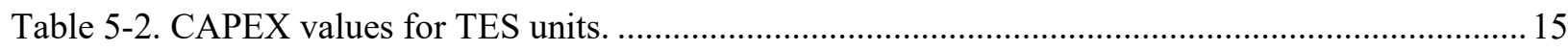

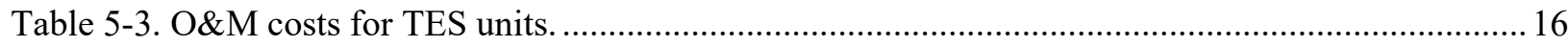




\section{ABSTRACT}

Energy storage technologies offer a promising solution to electric grid stability issues associated with the integration of variable renewable generators. The capability to match the electrical power output to instantaneous fluctuations in grid demand is crucial to ensure continuity of service. Including energy storage capability in an integrated energy system (IES) can provide the flexibility needed to meet variable electric demand and reduce the load following demands place on the reactor. In this report, economic data collected for energy storage (ES) technologies are described to support the objective of assessing the profitability of ES integration within the IES framework. In particular, there is a growing interest in thermal energy storage (TES) given its unique capability for long-duration storage for improving electricity reliability at a low levelized cost.

It is common practice to evaluate the total lifetime cost and profitability before commercializing new technologies. In this report we identify and examine the models needed to better understand the economics of thermal energy storage. We extend the TES cost model in RAVEN in the context of a balance of plant (BOP) that incorporates thermal storage. To focus the discussion, following a general overview of the most promising TES technologies, we consider a use case that involves a sensible heat, two-tank, molten-salt system. Structural and operational details are reported to identify the source of construction capital expenditure and operation and maintenance cost. A detailed description of the different cost items is provided as well as the cost scaling with different storage capacity and power ratings for capacity optimization purpose. In addition, the capital expenditure and the recurring cost of representative two-tank, molten salt coupled with concentrated solar plants are provided for readers' reference.

The ES use case is noteworthy as it is in the pilot stage of commercialization. We identify those areas that would benefit from an increased economic focus to obtain a more complete compilation of cost data. We also describe the thermal coupling issues that arise from integration of the two-tank molten salt thermal energy storage system with a BOP, which is the subject of our current research. Some components of costs will need to be evaluated through dedicated technoeconomic analysis in future modeling activities using modeling procedures proposed in this report. With the data presented and the procedures described in this report, sufficiently accurate models can be implemented for the solution of both the power dispatch and the capacity expansion problems within the RAVEN-based HYBRID framework. 


\section{ACRONYMS}

\begin{tabular}{|c|c|}
\hline BOP & Balance of Plant \\
\hline CAPEX & Capital Expenditure \\
\hline CSP & Concentrated Solar Power \\
\hline $\mathrm{CT}$ & Cold Tank \\
\hline $\mathrm{DC}$ & Direct Current \\
\hline DOD & Depth of Discharge \\
\hline ES & Energy Storage \\
\hline HT & Hot tank \\
\hline IES & Integrated Energy System \\
\hline IHX & Intermediate Heat Exchanger \\
\hline IRR & Internal Rate of Return \\
\hline LP & Low Pressure \\
\hline O\&M & Operation and Maintenance \\
\hline OTSG & Once Through Steam Generator \\
\hline PI & Profitability Index \\
\hline PCM & Phase Changing Materials \\
\hline RAVEN & Risk Analysis Virtual Environment \\
\hline RTE & Round-trip Efficiency \\
\hline SG & Steam Generator \\
\hline SMR & Small Modular Reactor \\
\hline TEAL & Tool for Economic AnaLysis \\
\hline TES & Thermal Energy Storage \\
\hline UTES & Underground Thermal Energy Storag \\
\hline
\end{tabular}




\section{INTRODUCTION}

\subsection{Short-duration vs Long-duration energy storage technologies}

Energy storage (ES) technologies are seen as a secure and economical solution to meet load demand and ensure stability in a grid with variable renewable generators. The influx of supply from solar and wind power has resulted in increased net demand variability on the grid. The capability to match the electrical power output to instantaneous fluctuations in demand is crucial to ensure continuity of service.

It is not unexpected to see consideration of inclusion of an ES unit in the integrated energy system (IES) framework. Renewable energy production is often incentivized and allows for profitable operation even at negative selling price. This change in market dynamics may necessitate a paradigm shift in the operation of baseload power plants if they are to be economically viable. Electrical, mechanical, chemical, electro-chemical and thermal energy storage technologies are being researched globally in attempts to enhance economic viability [1]. For base-load units (e.g., nuclear power plant), ES technologies offer the ability to supply electricity during peak demand periods without having to run the unit in the load-following mode. ES is seen as economically advantageous to generating assets with large daily diurnal power output swings, such as concentrated solar power (CSP) plants, where stored energy can be used to levelize overall power output. ES technologies can be coarsely categorized based on the length of storage duration, i.e., short-duration and long-duration.

- Short-duration (1-4 hours) technologies are usually used in to improve power quality, particularly to maintain the voltage and frequency stability in power systems during transients [2]. Short-duration technologies can also contribute to the grid congestion management [3]. In such applications, a fast switch time between charging and discharging mode is critical, which leads the lithium-ion batteries to be the dominant storage technology representing $\sim 90 \%$ of the market. Competing technologies are less attractive for most applications given lithium-ion's advantages in commercial acceptance, price, energy density and availability [4].

- Long-duration (> 6 hours) technologies include renewable energy off-peak storage (5-10 hours), wholesale energy arbitrage (2-10 hours) and commercial and industrial power reliability (4-10 hours) [5]. Lithium-ion technology is less competitive in long-duration applications as the cost of lithium-ion unit per $\mathrm{kWh}$ does not decline at incremental durations past six hours. In addition, its significant annual capacity degradation leads to larger maintenance cost.

\subsection{Overview of Thermal Energy Storage technologies}

Among long-duration technologies, thermal energy storage (TES) is emerging as a promising solution to lower the costs and improve the electricity reliability service. TES uses relatively inexpensive energy storage materials to decrease the marginal capital cost with increasing capacity 
(particularly at large capacities) and is characterized by comparatively low recycling costs. The power and energy-storing capacity are independently scalable, thus providing more flexibility in design. Besides, if TES units are operated within the thermal constraints, annual capacity degradation phenomena can be neglected [6]. Utilities are showing growing interest in TES solutions as more projects reach pilot stages [4]. Ideal applications currently include grid resilience, resource adequacy and capacity services, through there are still concerns pertaining to relatively low round-trip efficiency and high charging costs. A downside involves scalability, i.e., TES units are large capital assets that are challenging to size in smaller-scale modular increments, whereas short-duration technologies can be scaled incrementally. Advantages and disadvantages of TES technologies are listed in Table 1-1.

Table 1-1. Advantages and disadvantages of TES technologies.

\begin{tabular}{ll}
\hline \multicolumn{1}{c}{ Advantages } & \multicolumn{1}{c}{ Disadvantages } \\
\hline $\begin{array}{l}\text { - Compatible with nuclear plant } \\
\text { steam pipeline }\end{array}$ & - $\begin{array}{l}\text { Lower energy density vs. competing } \\
\text { technologies }\end{array}$ \\
- Materials are generally inexpensive & $\begin{array}{l}\text { Challenging to increase capacity in } \\
\text { modular increments after installation }\end{array}$ \\
$\begin{array}{ll}\text { - Power and energy capacity are } \\
\text { independently scalable }\end{array}$ & $\begin{array}{l}\text { Operating performance is sensitive to } \\
\text { local climatic conditions }\end{array}$ \\
\hline
\end{tabular}

In Figure 1-1, the different TES options for that can be coupled with an IES are reported. They fall into three general categories, i.e., sensible, latent, and thermochemical storage. The only TES system that currently operates with multiple hours of storage is the sensible, two-tank, molten-salt system. The success of this solution is partially due to the constituent components, i.e., pumps, valves, tanks, and heat exchangers, that have demonstrated reliable operation at commercial scale. During low demand periods, the steam turbine is running at partial load. The design accepts the resulting surplus turbine-grade steam from the primary plant, such as base-load nuclear reactor, during charging process, and releases steam to the low-pressure turbine during the discharging process, making it directly couplable to the primary plant pipeline. This design concept can be constructed as an "add-on" unit to the primary plant, providing convenience in operation and maintenance (O\&M). The design also exhibits excellent $(>90 \%)$ round trip energy and exergy efficiency [1][7]. 


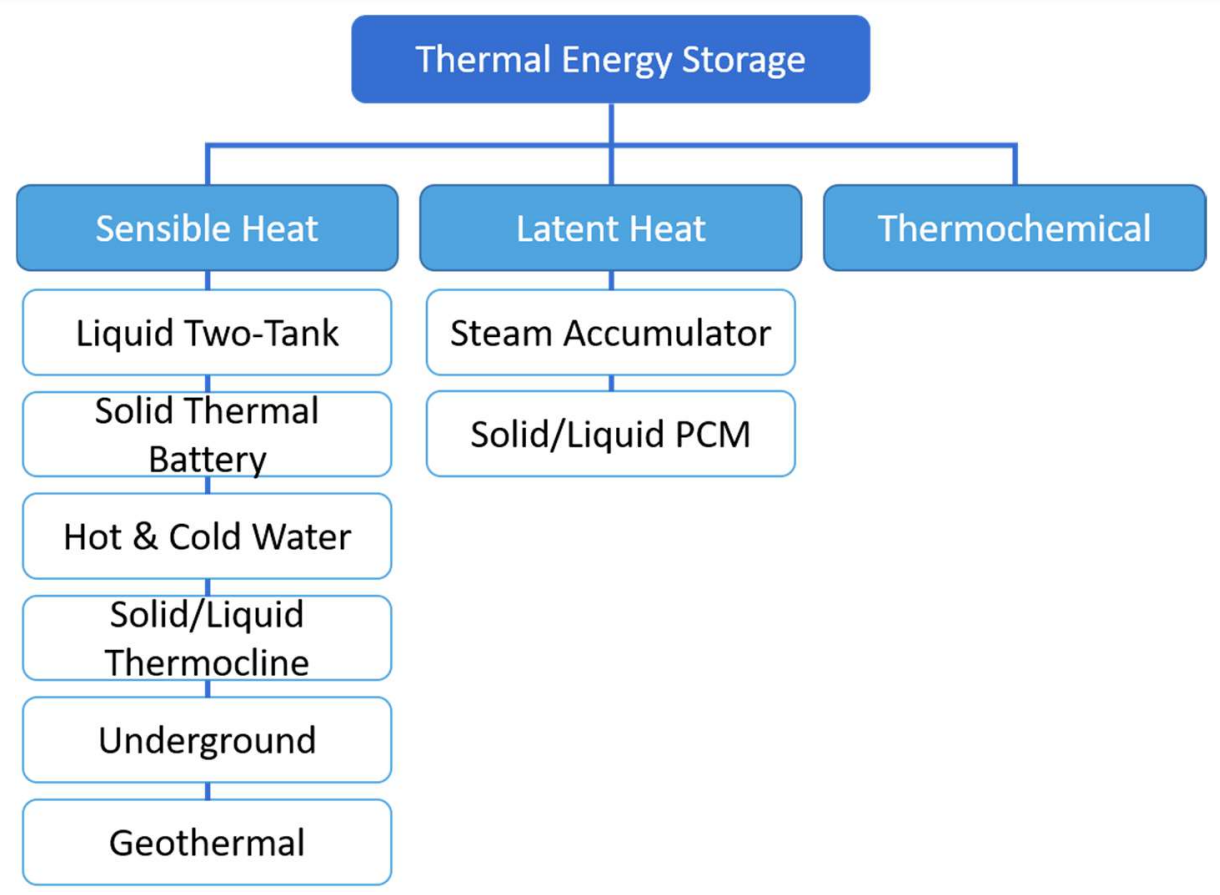

Figure 1-1. TES technologies that can be coupled with an IES [1].

As for the other TES technologies, a brief description is provided:

- The solid media thermal battery is a form of sensible heat storage using a solid structure, where the heat is directly stored through the temperature increase in the structure. The internal material stress due to thermal expansion and contraction in the structure places a constraint on the selection of materials, with firebrick and concrete being the major materials investigated recently due to their thermal expansion coefficient being nearly identical to steel, allowing the entire system to expand or contract without adding internal stress or losing heat transfer capability. A near-deployment stage technology is the concrete thermal battery [8], where the heat transfer fluid flows through a build-in U-tube steel pipe to deposit and withdraw heat into and from a single thermal battery. Such solid thermal batteries can be interconnected and stacked as a large-scale storage module, with a storage life exceeding 30 years.

- Hot \& cold water storage, underground thermal energy storage (UTES), and geothermal storage use water for peak heating and cooling utilizing the large heat capacity of water. These technologies involve the separation of hot and cold water in different storage tanks or wells, and water is pumped from hot well to cold well for heating and from cold well to hot well for cooling. As for the main differences between these technologies, UTES utilizes the near-surface wells to store water for seasonal heat storage, as a common practice in some north European countries [9]; hot and cold water storage can use above-ground storage tanks and be coupled with small modular reactors (SMR) [9]; geothermal storage usually involves 
the hot and cold wells at deep locations and uses the high hydrostatic pressure to keep the water in liquid phase at high temperature, aiming at higher heat transfer efficiency [10].

- Thermocline systems offer an opportunity for reducing TES costs. The cost benefit of thermoclines is significant, especially if the storage material is low-cost and configured in a self-supporting structure. In this case, the structural requirements of the containment vessel can be reduced. Thermocline systems can also adapt one-tank geometry with liquid materials as heat storage fluid, however, thermoclines have more complex operating requirements than the two-tank, molten-salt system, which creates the potential for utilization and performance losses [1].

- Steam accumulator allows storing energy in the accumulator in the format of a saturated water-steam mixture. The inserted steam will be mixed with the liquid in the bottom of the control volume and increase the system pressure during charging process, while the saturated liquid will flash evaporate to steam under a lowered pressure during discharging process. Despite its reasonably high energy storage density $\left(20-30 \mathrm{kWh} / \mathrm{m}^{3}\right)$, steam accumulators do face size limitations as hoop stresses begin to limit the vessel size. In addition, steam accumulators have sliding pressure discharge, which may not be desirable depending on the system application [11].

- Solid/liquid phase changing materials (PCMs) can be used to increase stored-energy density. PCMs have both latent and sensible enthalpies that contribute to the stored-energy density, providing a potential benefit over purely sensible systems. PCM systems suffer from a limitation in heat transfer during the discharge process due to the generally low thermal conductivity of the solid phase. (The exception to this case is metal PCMs; however, cost prohibits the use of most metal PCM candidates.) The heat transfer limitation causes low power density in PCM systems and will need to be overcome if PCM storage is to become a viable alternative. PCM storage is the most compatible storage system for the parabolic dish/Stirling concentrator because thermal energy delivery to the engine is isothermal, matching the operating conditions for that cycle [1].

- Thermochemical energy storage involves reversible chemical reactions where energy is stored in an endothermic reaction and released by the reverse exothermic reaction. Theoretically, thermochemical energy storage has the highest energy storage density capability among all the thermal storage technologies. However, several significant challenges need to be addressed before making it commercially available, such as the heat removal from chemical reactors and the separation of materials in both stages of reversible reactions [12][13]. Thermochemical storage is still in theoretical design and laboratory experiment stages.

For comparison purpose, ES systems are rated in terms of both instantaneous power capacity and potential energy output, where the former is defined as the maximum output of the invertor (MW) under specific operational and physical conditions, and the latter is defined as the maximum amount of energy (MWh) the system can store at one point in time. Both capital costs divided by 
instantaneous power capacity and capital cost divided by potential energy output are common industry conventions for cost quoting [4]. This report mainly focuses on the discussion of a designbased cost model for the molten salt, two-tank sensible heat storage unit, including both capital cost and O\&M cost in terms of instantaneous power capacity and potential energy output. In addition, several observations that might help improve the cost model are also discussed.

\section{CHARACTERIZATION OF THE ECONOMICS OF TES TECHNOLOGIES}

In Table 2-1, both the operational and economic parameters characterizing a TES technology are listed. The contribution of each parameter to the economic outcome are described in this chapter.

- Power rating is the maximum electrical power output. A higher power rating usually leads to larger size and higher cost of energy converter that converts stored energy to other forms for electricity generation. In addition, since a higher power rating may be achieved through higher temperature gradient in the heat exchanger, more sturdy material might be needed in this case which increases the cost.

- Nameplate capacity is directly related to the total cost of ES material, e.g., molten salt, concrete, firebricks, etc. In addition, more material is needed to construct the liquid thermal energy storage medium containers for a larger capacity.

- "DOD" denotes depth of discharge, i.e., the percent of the stored energy content that is discharged. Depth of discharge of $90 \%$ indicates that a fully charged energy storage system discharges $90 \%$ of its energy. TES can afford $100 \%$ DOD with negligible degradation of capacity and performance over years [14], which is superior to traditional battery-based unit that a higher DOD usually leads to reduced lifespan of the unit [15].

- Cycle/Day and Days in a year indicate the frequency of performing charging/discharging cycle of $100 \%$ DOD for a specific unit. The annual cycle frequency is a case-specific number that can range from 200 to 700 [16][17][18][19]. A higher cycle frequency yields to higher duty-cycle of power converting systems in both charging and discharging processes, leading to elevated O\&M cost.

- Round-trip efficiency (RTE) is the ratio of the output energy to the input energy in a charging/discharging cycle. For battery-based storage systems, the energy represented by a charge-balanced pulse will depend on the voltage response encountered [20]. Due to the rise in voltage on charging, and decline on discharging, sending a fixed amount of charge to the battery always requires more energy than the energy retrieved in releasing the same amount of charge, yielding an RTE from $60 \%$ to $90 \%$. However, the RTE can range from $70 \%$ to $100 \%$ in thermal energy storage systems [21]. The RTE of TES systems depends on the temperature difference of both charging side and discharging side, so that in climates that have large daily diurnal temperature swings, small TES can operate at greater than $100 \%$ RTE. Under these conditions, RTE becomes the ratio of energy out to energy in: 


$$
\eta_{R T E}=\frac{E o u t}{E \text { in }}
$$

- Charging costs are defined as the costs for purchasing the energy to charge the system. Such charging cost depends on the technologies and the total electricity generated in each year, and it is usually calculated for the technologies where the charging power are provided by sources that are available in market such as electricity or fossil fuel.

- Battery degradation per annum represents the degradation of the storage system where the installed capacity is not constant throughout the service lifetime of the energy storing unit. The capacity degrades over time due to multiple factors such as the storage medium degradation from extreme operating conditions, oxidation of anodes, leakage of storage medium, etc. The degradation rate of available capacity will contribute to the O\&M cost.

Table 2-1. Operational and economic parameters characterizing an energy storing technology.

\begin{tabular}{|c|c|}
\hline Parameter & Definition \\
\hline Power rating (MW) & Maximum power output \\
\hline Nameplate capacity (MWh) & $\begin{array}{l}\text { Total battery energy content ( } 100 \% \text { charge or "usable energy"). } \\
\text { Usable energy divided by power rating (in MW) reflects hourly } \\
\text { duration of system. }\end{array}$ \\
\hline Storage duration $(\mathrm{h})$ & Duration of the energy storing at maximum power rating \\
\hline Cycle/day (-) & Number of cycles ( $90 \%$ amplitude) in a day \\
\hline Days in a year (-) & $\begin{array}{l}\text { Number of days of system operation per calendar year. This } \\
\text { parameter, multiplied by the number of cycles in a day, gives } \\
\text { the number of charge/discharge cycles in a year. }\end{array}$ \\
\hline Round-trip efficiency (-) & See Eq.(1) \\
\hline Battery degradation per annum (-) & $\begin{array}{l}\text { Yearly reduction of the TES unit capacity throughout the } \\
\text { project life }\end{array}$ \\
\hline Total charging cost $(\$ / \mathrm{MWh})$ & $\begin{array}{l}\text { Total cost of charging scenarios as the cost of charging energy } \\
\text { purchase. }\end{array}$ \\
\hline Total O\&M cost (\$/MWh) & $\begin{array}{l}\text { Total Operation and Maintenance cost of charging/discharging } \\
\text { scenarios. This parameter, summed to the total cost during } \\
\text { charging scenarios, gives the total operating cost. }\end{array}$ \\
\hline Project life (years) & Service lifetime of the unit \\
\hline Total installation cost (\$/MWh) & Initial investment cost \\
\hline Economy of scale factor $(-)$ & $\begin{array}{l}\text { Factor accounting for the dependence of Investment cost from } \\
\text { the unit installed capacity }\end{array}$ \\
\hline
\end{tabular}




\section{ECONOMIC MODEL IMPLEMENTED IN TEAL}

The Tool for Economic AnaLysis (TEAL) is a financial performance calculator plugin for the Risk Analysis Virtual Environment (RAVEN) framework. One generalized module within the TEAL software called TEAL.CashFlow can compute the Net Present Value (NPV), Internal Rate of Return (IRR) and the Profitability Index (PI) for both capital expenditures (CAPEX) and recurring cost such as O\&M cost, considering multiple factors including component lifetime, inflation rates, taxation, and escalation factors [22]. TEAL.CashFlow module has been written using the script language Python, and its capability to provide financial risk and probabilistic metrics can empower RAVEN to perform optimization and analysis driven by financial risk augmentations. The relationship implemented in TEAL.CashFlow module that expresses the cash flows in year " $y$ " for both the capital expenditure (CAPEX) and the recurring costs is reported in Eq.(2).

$$
C F_{y}=m u l t \cdot \alpha_{y} \cdot\left(\frac{\text { driver }_{y}}{r e f}\right)^{X}
$$

Capacity expansion problems are solved through the optimization of the nameplate capacity and the power ratings yielding a minimized total CAPEX and recurring cost over the service lifetime of the studied units. Some of the TES costs items scale with the capacity, while others scale with power (Table 3-1). From this standpoint, the driver $y$ is often the unit capacity or unit power based on the functional dependence of individual cost categories.

Table 3-1. TEAL.CashFlow parameters and their definitions.

\begin{tabular}{|c|c|c|c|}
\hline Parameter & Capital Expenditures & $\begin{array}{c}\text { Recurring Costs - } \\
\text { Capacity Dependent }\end{array}$ & $\begin{array}{c}\text { Recurring Costs - } \\
\text { Power Dependent }\end{array}$ \\
\hline ref & \multicolumn{2}{|c|}{ Capacity of the reference unit } & Power of the reference unit \\
\hline driver $_{y}$ & \multicolumn{2}{|c|}{ Actual unit capacity } & Actual unit power \\
\hline$\alpha_{y}$ & $\begin{array}{c}\text { CAPEX of the reference } \\
\text { unit (capacity equal to } r e f \text { ) }\end{array}$ & $\begin{array}{c}\text { Recurring cost of the } \\
\text { reference unit } \\
\text { (capacity equal to } r e f \text { ) }\end{array}$ & $\begin{array}{c}\text { Recurring cost of the } \\
\text { reference unit } \\
\text { (power equal to } r e f \text { ) }\end{array}$ \\
\hline$X$ & \multicolumn{3}{|c|}{ Economy of scale factor } \\
\hline
\end{tabular}

\section{COUPLING OF TES TECHNOLOGY WITH IES}

As mentioned in Section 1.2, the most promising TES technology that has already been demonstrated in grid-level applications is the sensible, two-tank, molten-salt system. The coupling of this TES technology with a IES system was already studied and dedicated operational transients were simulated within this project [23][24]. The corresponding configuration is represented in Figure 4-1. The hydraulic loop consists of two large storage tanks along with pumps to transport 
the TES fluid between the tanks, the intermediate heat exchanger (IHX), and a once-through steam generator (OTSG). As for the coupling with the IES, the nuclear reactor is interfaced with a Steam Generator (SG) that produces a high-quality steam flow rate that is directed to the balance of plant (BOP) for the electricity production. During low-demand periods, a portion of this steam flow rate is diverted to the TES unit through the auxiliary bypass valves where it condenses on the shell side of the IHX. TES fluid is pumped from the cold tank (CT) to the hot tank (HT) through the tube side of the IHX at a rate sufficient to raise the temperature of the TES fluid to some desired value. The TES fluid is then stored in the hot tank at constant temperature. Condensate is collected in a hot well below the IHX and drains back to the main condenser. Details about the "charging" and the "discharging" operation modes are provided in Sections 4.1 and 4.2. Corresponding graphical representation are provided in Figure 4-2.

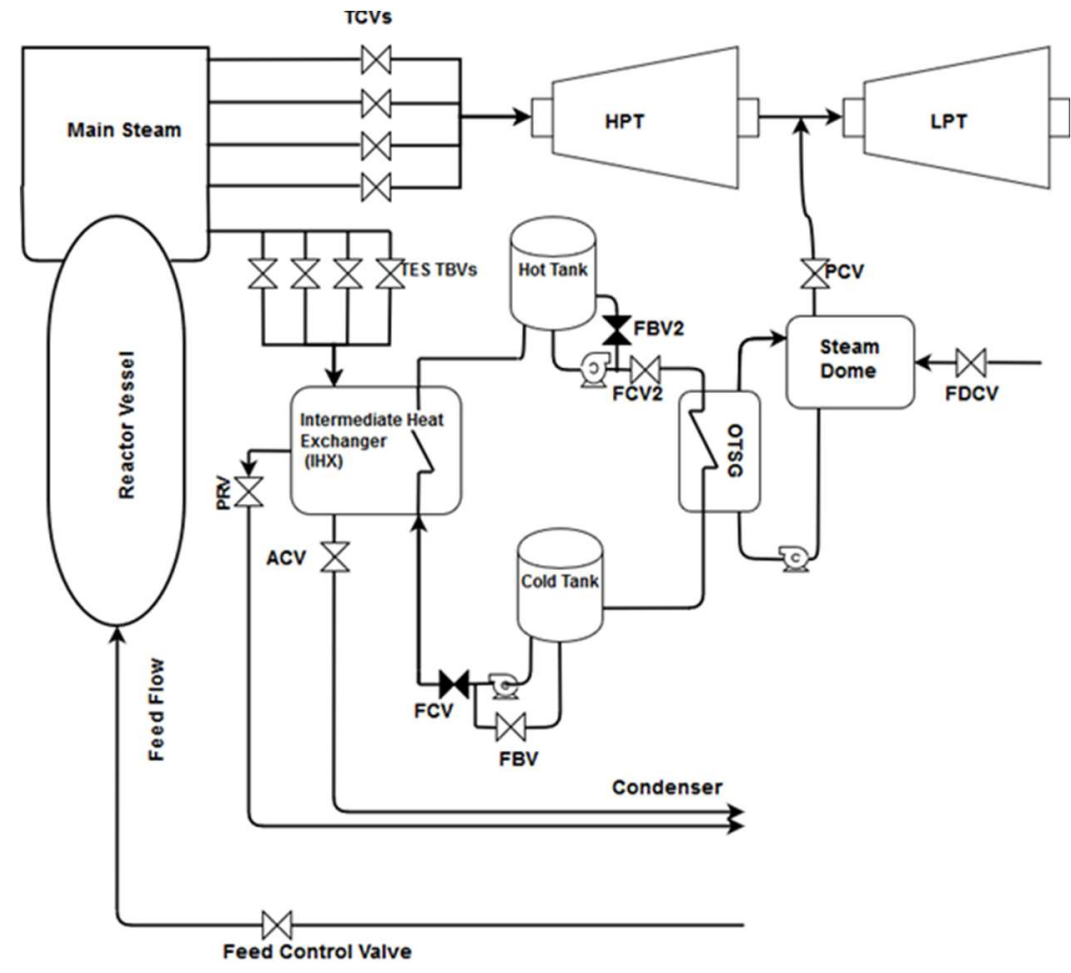

Figure 4-1. Configuration of the studied TES system [23].

\section{1. "Charging" mode}

During charging mode operation, the IHX exit temperature on the inner loop and the level in the IHX are controlled by adjusting the valve that regulates the flow from the CT to the HT. The TES fluid flow rate that flows through the IHX hydraulic circuit is a function of the steam flow rate diverted from the BOP. All other variables including IHX pressure, tank levels, inner loop mass flow rate, and heat transfer across the IHX are determined from the mass, energy, and momentum balances on the system. Pressure relief lines connect the shell side of the IHX with the condenser to prevent over-pressure scenarios during periods of low condensation rate [24]. The main constraint is associated to the filling of the HT. When it is nearly full and the system is in 
"charging" mode, the amount of steam diverted from the BOP needs to be decreased. Should the HT fill up, the storing capacity of the system is saturated, and then the pressure relief valves in the IHX will open when the stop valve between the CT and HT closes. From that moment on, all the diverted steam needs to be directly disposed to the condenser.

\section{2. "Discharging" mode}

During periods of peak demand, the system is discharged by pumping TES fluid from the HT to the CT through the tube side of the OTSG by producing a saturated liquid-vapor mixture. Saturated steam component is then reintroduced into the power conversion cycle prior to the moisture separator/reheaters before entering the low-pressure (LP) stages of the steam turbine. As with the TES operation in "charging mode", the main constraint to be addressed during the "discharging mode" is associated to the filling of the CT. If it is completely filled, then the hot fluid from the HT cannot be discharged any more, and the electricity production capability is run out [24].

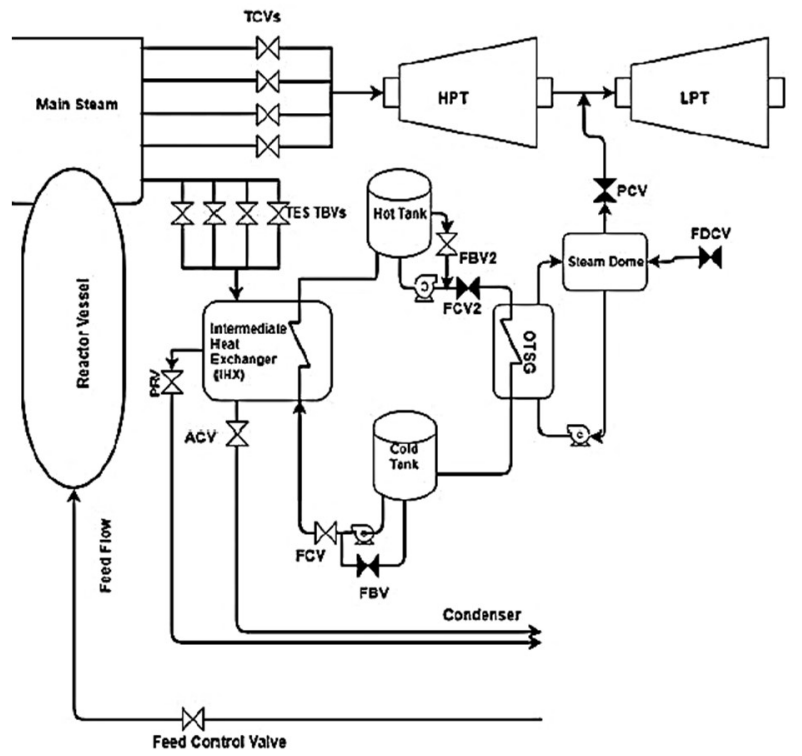

(a)

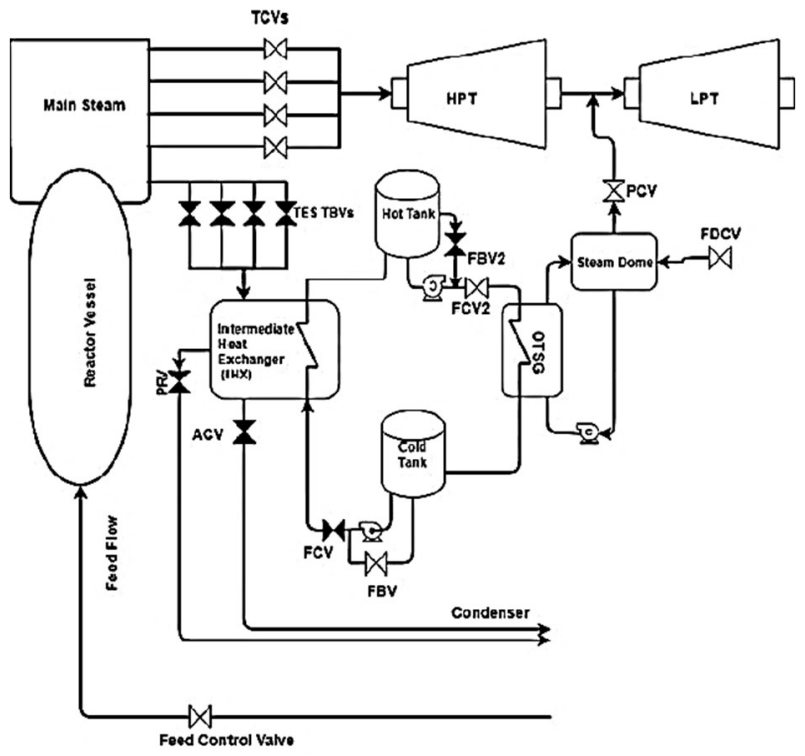

(b)

Figure 4-2. TES configuration in (a) "charging mode" and in (b) "discharging mode" [23].

\section{ECONOMIC DATA TO BE USED IN TEAL MODEL}

In this section, the data collected from a literature review about the major cost items for TES are presented. Different sources were used. The way figures are reported should allow a straightforward implementation in TEAL model. Most of the available data come from references describing concentrating solar power (CSP) plants (Table 5-1). In Figure 5-1, the layout of a CSP plant is shown. It is constituted by the collector system, the tower/receiver system, the two-tank TES and the steam Rankine energy conversion cycle. With regard to the definition of cost models for IES, our attention is focused on a small portion of the unit, i.e., the two-tank thermal energy 
storage (labelled as "THERMAL STORAGE SYSTEM" in Figure 5-1). Since the two-tank TES is meant to be coupled with the BOP, the contribution of the TES needs to be isolated. Unfortunately, most of the available data do not discriminate between the different portions of the system, and this is going to affect the reusability of some figures that will need to be derived for this application by means of dedicated techno-economic analysis.

Figure 5-1. Schematic of a molten salt power tower showing major subsystems (please refer to [25]).

Table 5-1. Economic parameters for selected CSP units.

\begin{tabular}{lccc}
\hline Parameter & $\begin{array}{l}\text { Xina Solar One } \\
\text { Power Plant }\end{array}$ & Arenales CSP Plant & $\begin{array}{c}\text { Redstone Solar } \\
\text { Thermal Power Project }\end{array}$ \\
\hline Power rating $\left(\mathrm{MW}_{\mathrm{t}}\right)$ & $100.0[26]$ & $50.0[26]$ & $100.0[26]$ \\
Nameplate capacity $\left(\mathrm{MW}_{\mathrm{t}} \mathrm{h}\right)$ & $550.0[26]$ & $350.0[26]$ & $1200.0[26]$ \\
Storage duration $(\mathrm{h})$ & $5.5[26]$ & $7.0[26]$ & $12.0[26]$ \\
Cycle/day (-) & $3[16]$ & $4[27]$ & $2[28]$ \\
Days in a year (-) & $230[16]$ & $120[27]$ & $200[28]$ \\
Project life (years) & 20 & 25 & 30 \\
\hline
\end{tabular}

\subsection{Capital expenditure (CAPEX)}

In Table 5-2, the CAPEX values are reported. Given the scaling of this parameter for ES units (Table 3-1), the collected values are provided along with the corresponding installed capacity.

Table 5-2. CAPEX values for TES units.

\begin{tabular}{lccc}
\hline Parameter & Ref. [29] & Ref. [25] & Ref. [30] \\
\hline Nameplate capacity (MWh) & 16 & 1580 & 750 \\
CAPEX & $15.5-24.9 \$ / \mathrm{kWh}^{1}$ & $30-35.5 \$ / \mathrm{kWh}$ & $31 \$ / \mathrm{kWh}$ \\
\hline
\end{tabular}

\subsection{Operation and Maintenance (O\&M) costs}

O\&M cost in TES comes from multiple sources due to the material/component property and operational activities. O\&M costs can be grouped into 4 categories according to the scaling:

- Fixed cost, due to the nearly constant administrative and operational crew size for the TES plant with different capacity and power rating [31];

- Nameplate capacity scaled cost, such as the molten-salt freeze protection [30], and the routine maintenance of the storage tank;

\footnotetext{
${ }^{1}$ This value was converted in $(\$ / \mathrm{kWh})$. The original value was $13-21 € / \mathrm{kWh}[29]$.
} 
- Power rating scaled cost, such as the routine service of pipe, valve and sealing [31];

- Electricity generation scaled cost, including the electricity to operate pumps, the fuel for reheaters, and the service/replacement of heat exchanger [32].

O\&M costs of two representative TES units, along with the corresponding installed capacity, power rating and electricity generation, are reported in Table 5-3.

Table 5-3. O\&M costs for TES units.

\begin{tabular}{lcc}
\hline Parameter & Ref. [33] & Ref. [30] \\
\hline Nameplate capacity $\left(\mathrm{MW}_{\mathrm{t}} \mathrm{h}\right)$ & 300 & 750 \\
Power rating $\left(\mathrm{MW}_{\mathrm{t}}\right)$ & 50 & 50 \\
Electricity generation $\left(\mathrm{GW}_{\mathrm{e}} \mathrm{h} / \mathrm{yr}\right)$ & 200 & 250.9 \\
Total annual O\&M cost $(\mathrm{M} \$ \mathrm{yr})$ & 1.6 & 4.87 \\
\hline
\end{tabular}

\subsection{Charging costs}

As mentioned in Section 2, charging costs are defined as the costs incurred for the purchase of energy to charge the system annually. They can be directly calculated for technologies where the charging power are provided by sources that are available in market such as electricity or fossil fuel [34][35]. However, the two-tank TES unit discussed in this report works as an "add-on" unit of the reactor and uses the turbine-grade steam in its charging process, thus the charging cost is not applicable. Therefore, the only recurring cost related to the charging of two-tank TES is the O\&M cost.

\subsection{Economy of scale factor}

The scaling of the capital costs constitutes a particular application of Eq.(2). In particular, capital costs increase with the nameplate capacity (Eq.(3)).

$$
C_{y}=C_{x} \cdot\left(\frac{S_{y}}{S_{X}}\right)^{0.6}
$$

where $C_{x}$ and $S_{X}$ relate to the cost and nameplate capacity of the reference plant, whereas $C_{y}$ and $S_{y}$ relate to the cost and nameplate capacity of the actual plant. According to [36], this scale factor ensures an accuracy of $\pm 20 \%$. Another reference suggests that the correct scale factor for twotanks systems used in chemical process industries is 0.7 [7]. As reported in Section 3, some of the TES costs items scale with the capacity, while others scale with the power rating. To this aim, the applicability of the provided economy of scale factors is limited to the capital costs, i.e., they cannot be used for the scaling of other capacity-dependent recurring costs and power-dependent recurring costs. 
In Section 1.2, it was said that power and energy-storing capacity are independently scalable for an ES unit. Let us consider the case of TES. With regard to the design represented in Figure 41 , the components that define the energy-storing capabilities of a unit are the HT and the CT, i.e., the larger the size of the tanks, the larger the amount of thermal energy that can be stored during a charging cycle. As for the power production capability, it is determined by the associated energy conversion cycle, i.e., by the size of (1) the OTSG and (2) the steam turbine. This means that the assumption of independent scalability of power rating and the nameplate capacity is valid for TES unit as well. At the same time, there are other constraints deriving from the coupling of the TES with the BOP that need to be taken into account. As described in Section 4, the TES relies on the BOP steam turbine to produce electricity. When the TES is discharged and the extracted thermal energy is converted into electrical power, the generated steam flow rate at the OTSG outlet is reintroduced into the LP stages of the steam turbine. This means that the size of the BOP will impose limits to the power rating of the TES unit. For instance, let us assume that a TES unit characterized by a large nameplate capacity is designed, i.e., the molten salt tanks are huge. If the OTSG is large enough, a large steam flow rate can be generated, but the corresponding electrical power output will depend on the size of the steam turbine. If the BOP size is reduced, the size of the steam turbine will not allow processing that steam flow rate and an upper bound will limit the TES power rating. In conclusion, the thermal coupling of the TES with the BOP does affect the power rating, but it has no influence on the corresponding nameplate capacity.

\subsection{Round-trip efficiency (RTE)}

Given the specific design of the IES and the coupling of the TES with the BOP, RTE cannot be retrieved from literature, i.e., it needs to be evaluated through techno-economic analysis. In this Section, a definition of the RTE for the two-tank TES $\left(\eta_{R T E}\right)$ is then provided. According to Eq.(1), RTE is given by the ratio of the output energy to the input energy in a charging/discharging cycle. Let us first identify the streams of energy at the TES input/output:

- When the TES is in "charging" mode, a portion of the high-quality steam flow rate generated by the SG is diverted from the BOP and sent to the IHX to heat up the TES fluid that is eventually collected in the HT. In Figure 5-2, the specific enthalpy and the mass flow rate of the heating steam are outlined $\left(h_{1}, w_{1}\right)$.

- When the TES is in "discharging" mode, the TES fluid is flowing from the HT to the CT and a saturated steam flow rate is generated in the TES OTSG. In Figure 5-2, the specific enthalpy and the mass flow rate of the steam at the OTSG outlet are outlined $\left(h_{2}, w_{2}\right)$.

- During the "discharging" mode, the conditions of the water flow rate entering the "Steam Dome" and then the OTSG need to be taken into account. When estimating the RTE and the output energy that is extracted from the TES is evaluated, only the fraction of the initially stored thermal energy need to be considered. In Figure 5-2, the specific enthalpy and the mass flow rate of the water at the OTSG inlet are outlined $\left(h_{3}, w_{2}\right)$. 


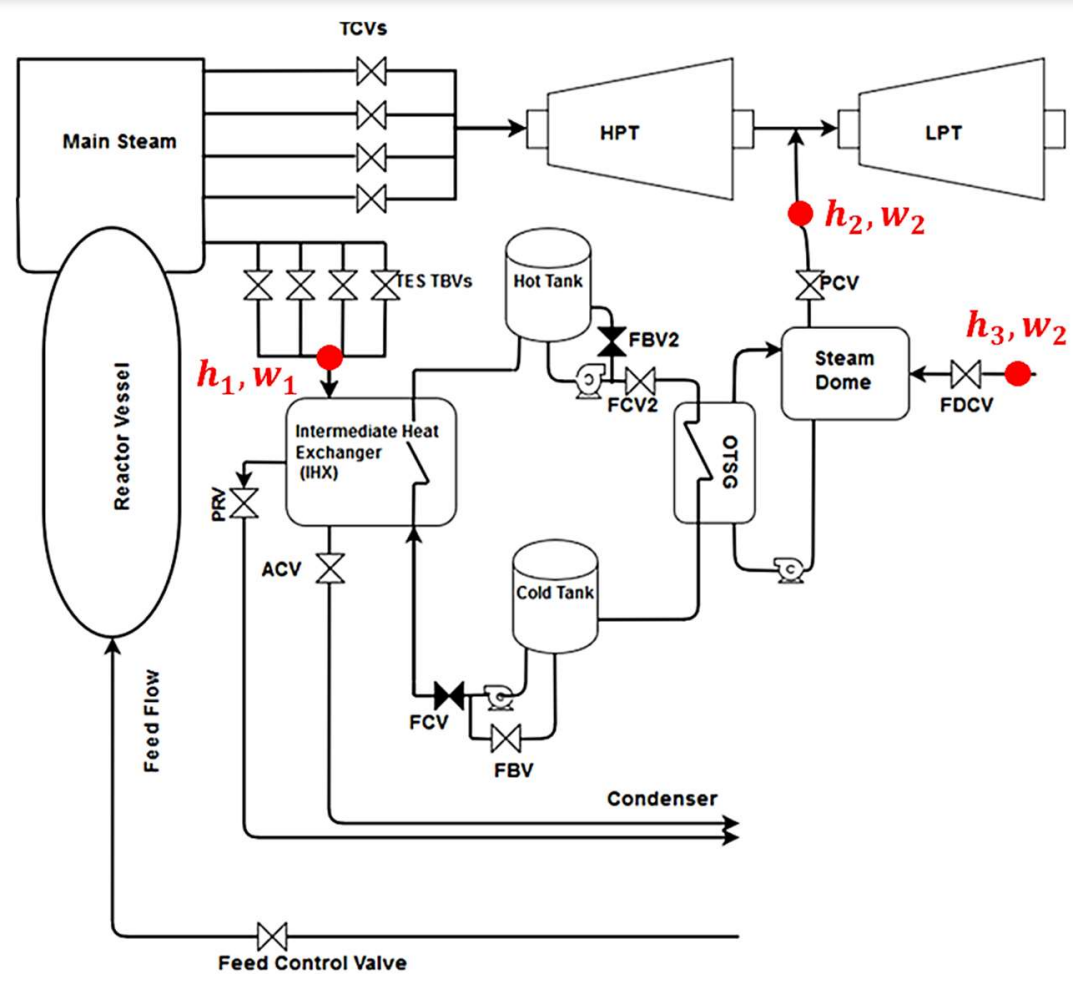

Figure 5-2. Configuration of the studied TES system. The thermodynamic conditions of the steam diverted to the TES and the conditions of the steam produced by the IHX are outlined.

The above-mentioned contributions describe the TES input/output thermal power flows. To evaluate the RTE, we need to refer to a charging/discharging cycle. To this aim, the TES input energy will be evaluated by referring to the transient that gets the HT from completely empty (HT(0\%)) to completely filled (HT(100\%)). The TES input energy can be obtained by integrating the input power stream from the beginning to the end of the charging cycle (it corresponds to the energy diverted from the BOP). Similarly, the TES output energy will be evaluated by referring to the transient that gets the HT from completely filled (HT(100\%)) to completely empty (HT(0\%)). The TES output energy can be obtained by integrating the net output power stream from the beginning to the end of the discharging cycle. In Eq.(4), the ensuing definition of RTE is provided.

$$
\eta_{R T E}=\frac{\int_{\mathrm{HT}(100 \%)}^{\mathrm{HT}(0 \%)}\left(h_{2}-h_{3}\right) w_{2} d t}{\int_{\mathrm{HT}(0 \%)}^{\mathrm{HT}(100 \%)} h_{1} w_{1} d t}
$$

\subsection{Installed capacity degradation}

Usually, energy storage technologies suffer installed capacity degradation throughout the service lifetime. According to [6], this effect can be considered negligible for TES.

\subsection{Project lifetime}

TES units usually have a service lifetime between 20 and 30 years [26][16][27][28]. 


\section{CONCLUSIONS}

In this work, the major cost items that are used to characterize the economics of TES units were presented and discussed. After a brief overview of the most promising TES technologies, we focused on the sensible, two-tank, molten-salt system. The data were retrieved from references describing CSP plants. This aspect represented an issue since the data referred to the whole plants, whereas our focus is the energy-storing portion. In particular, most of the capital expenditure figures did not discriminate between the different portions of the system. Besides, the integration of a TES unit with a BOP within an IES is a recent research problem, and the constraints ensuing from the designed thermal coupling are still to be explored. For these reasons, some cost items need to be derived by means of dedicated techno-economic analysis in future TES modeling activities. Dedicated modeling procedures were proposed. For instance, the traditionally adopted paradigm for the scaling of the capacity and the power rating of TES units needs to be modified to account for the BOP size-imposed constraints. In addition, a dedicated model-based approach was developed to quantify the round-trip efficiency of the studied design, starting from the currently accepted definition of RTE. Overall, the collected data and the described procedures will allow implementing sufficiently accurate models for the solution of both the power dispatch and the capacity expansion problems within the RAVEN-based HYBRID framework. 


\section{REFERENCE}

[1] D. Mikkelson, K. Frick, S. Bragg-Sitton, C. Rabiti, J.M. Doster, "Initial Performance Evaluation and Ranking of Thermal Energy Storage Options for Light Water Reactor Integration to Support Modeling and Simulation", INL/EXT-19-56504, Revision 0, (2019).

[2] J.O.G. Tande, "Grid integration of wind farms", Wind Energy: An International Journal for Progress and Applications in Wind Power Conversion Technology, 6(3), 281-295 (2003).

[3] A. Price, S. Bartley, S. Male, G. Cooley, "A novel approach to utility-scale energy storage", Power Engineering Journal, 13(3), 122-129 (1999).

[4] Lazard Ltd., "Lazard's levelized cost of storage analysis - version 6.0”, https://www.lazard.com/, (Last consulted on March 23, 2021).

[5] A.A. Akhil et al., "DOE/EPRI 2013 electricity storage handbook in collaboration with NRECA", Sandia National Laboratories (2013).

[6] C.S. Lai, G. Locatelli, "Economic and financial appraisal of novel large-scale energy storage technologies", Energy, 214 (2021).

[7] G. Glatzmaier, "Developing a Cost Model and Methodology to Estimate Capital Costs for Thermal Energy Storage”, Technical Report NREL/TP-5500-53066 (2011).

[8] N. Hoivik et al., "Demonstration of Energy Nest thermal energy storage (TES) technology", AIP Conference Proceedings, 1850(1), 080011 (2017).

[9] Underground Energy, "ATES - Aquifer thermal energy storage". Available: https:/undergroundenergy.com/our-technology/ates/ (Last consulted on March 23, 2021).

[10] D. Wendt et al., "Geologic thermal energy storage of solar heat to provide a source of dispatchable renewable power and seasonal energy storage capacity", GRC Transactions, 43 (2019).

[11] W.D. Steinmann, M. Eck, "Buffer storage for direct steam generation", Solar Energy, 80(10), 1277-1282 (2006).

[12] B. Michel, N. Mazet, P. Neveu, "Experimental investigation of an innovative thermochemical process operating with a hydrate salt and moist air for thermal storage of solar energy: Global performance", Applied energy, 129, 177-186 (2014).

[13] M. Angerer et al., "Design of a MW-scale thermo-chemical energy storage reactor", Energy Reports, 4, 507519 (2018).

[14] C. Del Pero, N. Aste, H. Paksoy, F. Haghighat, S. Grillo, F. Leonforte, "Energy storage key performance indicators for building application", Sustainable cities and society, 40, 54-65 (2018).

[15] H. Ibrahim, A. Ilinca, J. Perron, "Energy storage systems - Characteristics and comparisons", Renewable and sustainable energy reviews, 12(5), 1221-1250 (2008).

[16] Power Technology, "Xina Solar One Thermo Solar Plant, Northern Cape Province". Available: https://www.power-technology.com/projects/xina-solar-one-thermo-solar-plant-northern-cape-province/ (Last consulted on March 23, 2021).

[17] E. Oró, A. Gil, A. De Gracia, D. Boer, L.F. Cabeza, "Comparative life cycle assessment of thermal energy storage systems for solar power plants", Renewable Energy, 44, 166-173 (2012).

[18] R.K. Sharma, P. Ganesan, V.V. Tyagi, "Long-term thermal and chemical reliability study of different organic phase change materials for thermal energy storage applications", Journal of Thermal Analysis and Calorimetry, 124(3), 1357-1366 (2016).

[19] F. Dinter, D. Mayorga Gonzalez, "Operability, reliability and economic benefits of CSP with thermal energy storage: first year of operation of ANDASOL 3", Energy Procedia, 49, 2472-2481 (2014).

[20] M. Safoutin, J. Cherry, J. McDonald, S. Lee, "Effect of Current and SOC on Round-Trip Energy Efficiency of a Lithium-Iron Phosphate (LiFePO4) Battery Pack", SAE 2015 World Congress \& Exhibition (2015).

[21] G. Miller, "Small thermal energy storage and its role in our clean energy future", Summer Study on Energy Efficiency in Buildings, 1-12 (2016).

[22] A.S. Epiney, P. Talbot, C. Wang, A. Alfonsi, "Tool for Economic AnaLysis (Teal) User Manual", Idaho National Laboratory (2021).

[23] K. Frick, J.M. Doster, S. Bragg-Sitton, "Design and Operation of a Sensible Heat Peaking Unit for Small Modular Reactors", Nuclear Technology, 205, 415-441 (2019).

[24] H. Wang, R. Ponciroli, R.B. Vilim, A. Alfonsi, "Validation and Demonstration of Control System Functional Capabilities within the IES Plug-and-Play Simulation Environment”, ANL/NSE-21/5 (2021). 
[25] C.S. Turchi, G.A. Heath, "Molten Salt Power Tower Cost Model for the System Advisor Model (SAM)", Technical Report NREL/TP-5500-57625 (2013).

[26] U.S. Department of Energy, Energy Storage Systems Program, "DOE OE Global Energy Storage Database". Available: https://www.sandia.gov/ess-ssl/global-energy-storage-database-home/ (Last consulted on March 23, 2021).

[27] Solar Thermal Energy News, "Concentrated Solar Power (CSP) plant Los Arenales taken into operation". Available: https://helioscsp.com/concentrated-solar-power-csp-plant-los-arenales-taken-into-operation/ (Last consulted on March 23, 2021).

[28] NS Energy, "Redstone Concentrated Solar Project". Available: https://www.nsenergybusiness.com/projects/redstone-concentrated-solar-project/ (Last consulted on March 23, 2021).

[29] A. Smallbone, V. Jülch, R. Wardle, A.P. Roskilly, "Levelised cost of storage for pumped heat energy storage in comparison with other energy storage technologies", Energy Conversion and Management, 152, 221-228 (2017).

[30] U. Herrmann, B. Kelly, H. Price, "Two-tank molten salt storage for parabolic trough solar power plants", Energy, 29(5-6), 883-893 (2004).

[31] H. Price, D. Kearney, "Reducing the cost of energy from parabolic through solar power plants", International Solar Energy Conference (ISES 2003), Hawaii Island (Hawaii), March 16-18 (2003).

[32] S.J.W. Klein, E.S. Rubin, "Life cycle assessment of greenhouse gas emissions, water and land use for concentrated solar power plants with different energy backup systems", Energy Policy, 63, 935-950 (2013).

[33] S. Hameer, J.L. Van Niekerk, "Thermodynamic modelling of thermal energy storage systems", Energy Procedia, 93, 25-30 (2016).

[34] T. Okazaki, "Electric thermal energy storage and advantage of rotating heater having synchronous inertia", Renewable Energy, 151, 563-574 (2020).

[35] L. Yao, Z. Damiran, W.H. Lim, "Optimal charging and discharging scheduling for electric vehicles in a parking station with photovoltaic system and energy storage system", Energies, 10(4), 550 (2017).

[36] R. Jacob, W. Saman, F. Bruno, "Capital cost expenditure of high temperature latent and sensible thermal energy storage systems", AIP Conference Proceedings 1850, 080012 (2017). 


\section{Argonne}

\section{Nuclear Science and Engineering (NSE) Division}

Argonne National Laboratory

9700 South Cass Avenue, Bldg. 208

Argonne, IL 60439

www.anl.gov

Argonne National Laboratory is a U.S. Department of Energy laboratory managed by UChicago Argonne, LLC 